\title{
Viability of equine embryos after puncture of the capsule and biopsy for preimplantation genetic diagnosis
}

\author{
Y H Choi ${ }^{1}$, A Gustafson-Seabury ${ }^{2}$, I C Velez ${ }^{1}$, D L Hartman ${ }^{3}$, S Bliss ${ }^{3}$, F L Riera ${ }^{4}$, J E Roldán ${ }^{4}$, \\ B Chowdhary ${ }^{2}$ and K Hinrichs ${ }^{1,5}$
}

Departments of ${ }^{1}$ Veterinary Physiology and Pharmacology and ${ }^{2}$ Veterinary Integrative Biosciences, College of Veterinary Medicine and Biomedical Sciences, Texas A\&M University, College Station, Texas 77843-4466, USA, ${ }^{3}$ Hartman Equine Reproduction Center, Whitesboro, Texas 76273, USA, ${ }^{4}$ Centro de Reproducción Equina Doña Pilar, 6070 Lincoln (B), Argentina and ${ }^{5}$ Department of Large Animal Clinical Sciences, College of Veterinary Medicine and Biomedical Sciences, Texas A\&M University, College Station, Texas 77843-4466, USA

Correspondence should be addressed to K Hinrichs at Department of Veterinary Physiology and Pharmacology, College of Veterinary Medicine and Biomedical Sciences, Texas A\&M University; Email: khinrichs@cvm.tamu.edu

\begin{abstract}
The equine embryo possesses a capsule that is considered essential for its survival. We assessed viability after breaching the capsule of early (Day 6) and expanded (Day 7 and 8) equine blastocysts by micromanipulation. The capsule was penetrated using a Piezo drill, and trophoblast biopsy samples were obtained for genetic analysis. Pregnancy rates for Day-6 embryos, which had intact zonae pellucidae at the time of recovery, were $3 / 3$ for those biopsied immediately after recovery and $2 / 3$ for those biopsied after being shipped overnight under warm $\left(\sim 28{ }^{\circ} \mathrm{C}\right)$ conditions. The pregnancy rates for encapsulated Day-7 expanded blastocysts were 5/6 for those biopsied immediately and 5/6 for those biopsied after being shipped overnight warm. Two of four encapsulated Day-8 blastocysts, 790 and $1350 \mu \mathrm{m}$ in diameter, established normal pregnancies after biopsy. Nine mares were allowed to maintain pregnancy, and they gave birth to nine normal foals. Biopsied cells from eight embryos that produced foals were subjected to whole-genome amplification. Sex was successfully determined from amplified DNA in 8/8 embryos. Identification of disease-causing mutations matched in the analyses of 6/6 samples for the sodium channel, voltage-gated, type IV, alpha subunit (SCN4A) gene and in 6/7 samples for the peptidylprolyl isomerase $B(P P I B)$ gene, in embryo-foal pairs. Thus, the capsule of the equine embryo can be breached without impairing viability. Further work is needed to determine whether this breach is transient or permanent. These findings are relevant to the understanding of equine embryo development and to the establishment of methods for micromanipulation and embryo cryopreservation in this species.

Reproduction (2010) $\mathbf{1 4 0} 893-902$
\end{abstract}

\section{Introduction}

The early equine embryo possesses a distinctive embryonic capsule. This acellular membrane forms after the entry of the embryo into the uterus, on late Day 5 after ovulation (Flood et al. 1982, Freeman et al. 1991). The equine capsule is composed of mucin-like glycoproteins that are produced by the trophoblast and likely modified by the uterine environment; it has great mechanical strength and is extraordinarily resistant to chemical or enzymatic solubilization (Oriol et al. 1993a, 1993b, Albihn et al. 2003). Capsular material first appears as an amorphous subzonal layer in the perivitelline space (Flood et al. 1982) and then coalesces to form the fibrillar capsule. As the encapsulated blastocyst expands, the zona thins and is shed about Day 7. The equine capsule has similarities in composition and time of formation to intrauterine modifications of the early embryonic coats found in many species, notably the neozona of the rabbit (Denker 2000, Herrler \& Beier 2000). However, while the rabbit embryonic coat starts to dissolve within a few days of the uterine entry, at the time of implantation (Day 7, Denker 2000), the equine capsule persists until about Day 21 of gestation (Enders \& Liu 1991, Betteridge 2007, Allen 2010), creating a physical barrier between the trophoblast and the uterine epithelium during this time.

The physiological role of the equine embryonic capsule is still unclear. It has been hypothesized to protect the conceptus during its extensive migration throughout the uterus (which occurs from uterine entry until Day 16), to keep the embryo spherical, to serve as a store and exchange area for the conceptus proteins, and to protect the conceptus from the maternal immune system (review, Stout et al. (2005)). In equine embryos produced by sperm injection, maternal cells have been shown to invade the perivitelline space through the defect in the zona caused by the micropipette; however, 
as the capsule forms, these cells are excluded from the underlying embryo (Choi et al. 2004).

Rabbit blastocysts recovered ex vivo can survive penetration of the embryo coats, both on Day 4, before formation of the neozona (Gardner \& Munro 1974, Babinet \& Bordenave 1980, Moens et al. 1996), and on Day 5.75, after its formation (Gardner \& Edwards 1968). Gardner \& Edwards obtained biopsy samples by the excision of trophoblast and overlying capsule from rabbit embryos over $2 \mathrm{~mm}$ in diameter, and $20 \%$ of these embryos produced apparently normal fetuses after transfer. However, because of the relatively early time of dissolution of the rabbit neozona, penetration of this structure may not carry the same import as does puncture of the more persistent equine capsule.

In the horse, loss of the embryonic capsule limits viability; embryos from which the capsule was mechanically removed did not establish pregnancy after transfer (Stout et al. 2005). When equine embryos were bisected, resulting in apparent loss of the capsular material and zona pellucida, the pregnancy rates were $23-67 \%$ for embryos bisected at the morula or early blastocyst stages, but 0/18 for expanded encapsulated blastocysts (McKinnon et al. 1989, Müller \& Cikryt 1989, Skidmore et al. 1989). It has therefore been postulated that secretion of the formative capsular material in the equine embryos is stage specific, possibly an activity of early uterine embryos but not of expanded blastocysts, and that breaching of the capsule of expanded blastocysts is fatal (Skidmore et al. 1989, Stout et al. 2005).

In a practical context, the capsule is implicated in the low success of embryo splitting in the horse and in the failure of expanded blastocysts to be successfully cryopreserved, despite decades of work in this area (Slade et al. 1985, Maclellan et al. 2002, Eldridge-Panuska et al. 2005, Barfield et al. 2009). Notably, although embryo biopsy for preimplantation genetic diagnosis (PGD) has been performed in humans since the early 1990's (review, Ogilvie et al. (2005)) and has an application for detection and elimination of inherited genetic errors in the horse, this procedure has not been established in equine embryos. In humans, PGD is performed on embryos produced in vitro; similarly, biopsy of in vitro-produced equine embryos, which do not form capsules (Tremoleda et al. 2003), would likely be uncomplicated. However, in the horse, in vitro embryo production is performed at only a few centers, is costly, and is inefficient relative to in vivo embryo collection. Thus, if PGD is to be a viable clinical procedure in horses, it must be performed on embryos recovered from mares after uterine flush.

To the best of our knowledge, there has been only one previous report on embryo biopsy in the horse. Huhtinen et al. (1997) used microblade dissection to biopsy embryos recovered on Day 6 and performed genetic sexing on the recovered cells. Transfer of 14 biopsied embryos yielded three pregnancies $(21 \%)$. If the secretion of capsular material is stage specific, then Day-6 embryos, as used by Huhtinen et al. (1997), would seem the best candidates for biopsy - although the low pregnancy rate attained in that study suggests that even these early embryos were compromised by the biopsy procedure. In practice, however, equine embryo recovery is rarely performed before Day 7 , as the small size of earlier embryos necessitates a longer search time with more chance of missing the embryo. Lower embryo recovery rates have been reported following uterine flushes on Day 6 than on later days (luliano et al. 1985, McKinnon \& Squires 1988, Battut et al. 1998). For these reasons, the equine embryos are typically flushed from the uterus on Day 7 or 8; at this stage, the blastocyst has expanded, the capsule is fully formed, and the zona pellucida has been shed from its surface (Betteridge et al. 1982). Breaching the capsule in such embryos may limit their viability. Furthermore, the resilience of the capsule (Stout et al. 2005) impedes its micromanipulation.

As noted above, PGD via embryo biopsy is commonly used in humans to determine the genetic status of at-risk embryos (Goossens et al. 2009). Establishment of a clinical method for PGD in the horse would be of consequence in the elimination of devastating equine genetic diseases such as hereditary equine regional dermal asthenia, glycogen branching enzyme deficiency, hyperkalemic periodic paralysis, polysaccharide storage myopathy, severe combined immunodeficiency disorder, and cerebellar abiotrophy (Rudolph et al. 1992, Bernoco \& Bailey 1998, Ward et al. 2004, Brault \& Penedo 2009, Herszberg et al. 2009, Tryon et al. 2009). Thus, the purpose of this study was to determine whether the capsule of early (Day 6) and expanded, encapsulated (Day 7 and 8) equine embryos could be breached via micromanipulation, whether the induced capsular defect affected embryo viability, and whether this approach could provide sufficient cells for genetic analysis.

\section{Results \\ Day-6 embryos}

Embryos recovered by uterine flush on Day 6 after ovulation were morulae, late morulae, or early blastocysts, as described by Stout et al. (2005). They were all enclosed by the zona pellucida; in early blastocysts, the capsules could be seen within the zonae, and the zonae were starting to thin. The embryos were subjected to biopsy either immediately $(n=3)$ or, as some embryos were obtained from a remote location, after storage overnight under various conditions $(n=9)$. The embryos had diameters of 159-245 $\mu \mathrm{m}$ (including zona) at the time of biopsy. After biopsy, the embryos were packaged in warm culture medium $\left(38.2^{\circ} \mathrm{C}\right.$; this temperature 
dropped slowly over shipment to $28^{\circ} \mathrm{C}$ ) and were shipped for 4-6 $\mathrm{h}$ before transfer to the recipient mares.

Photomicrographs of the embryos before and after biopsy are presented in Fig. 1. In Day- 6 morulae with full-thickness zonae, the capsular material was not evident during the biopsy procedure (Fig. 1a and b). In Day- 6 early blastocysts, the capsule became more evident after the zona was drilled. The capsule blocked the opening of the pipette, and on gentle aspiration, it could be seen entering the pipette. The Piezo drill was used to penetrate the capsule, after which aspiration only was used to collect the trophoblast cells. During the collection of trophoblast cells, the embryo mass became smaller due to the loss of cells and blastocoele fluid; the capsule could then be seen in the increased perivitelline space, appearing to have multiple folds (Fig. 1d). The capsule did not extrude through the hole in the zona. Interestingly, in Day-6 early blastocysts that had been held in warm medium overnight before biopsy, the
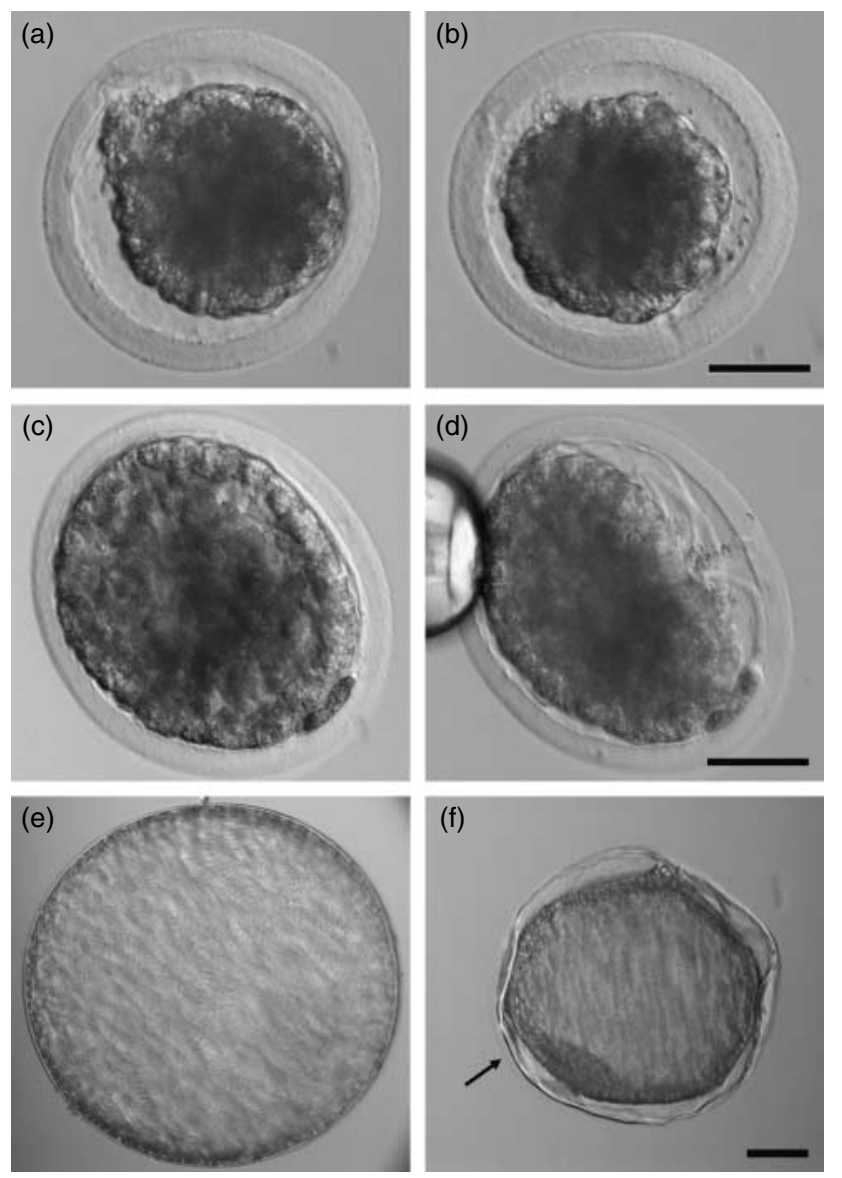

Figure 1 Photomicrographs of the equine embryos before (a, c, and e) and after (b, $d$, and f) micromanipulation to obtain a trophoblast biopsy sample via the Piezo drill. (a and b) Day-6 morula; (c and d) Day-6 early blastocyst; (e and f) Day-7 expanded blastocyst. Bar $=50 \mu \mathrm{m}$. Note the folded capsule in the perivitelline space of the early blastocyst (d) after micromanipulation. A shard of zona pellucida remains attached to the capsule of the Day-7 blastocyst (f, arrow). capsule did not show these characteristic folds; rather the capsule approximated the spherical outline of the embryo.

The results of transfer of biopsied embryos held under the various conditions are presented in Table 1. All three embryos biopsied immediately after recovery established pregnancies that developed normally as assessed by ultrasonography per rectum, with a heartbeat observed at 25 days. Nine Day- 6 embryos were held overnight or shipped overnight before the biopsy, three each under three different conditions. Five of these embryos (in the room temperature or warm treatments) were measured both before and after shipment; these embryos increased in diameter from an average of $181 \mu \mathrm{m}$ at the time of recovery to an average of $197 \mu \mathrm{m}$ at the time of biopsy. The pregnancy rates for the cold, room temperature, and warm overnight treatments were $0 / 3,1 / 3$, and $2 / 3$ respectively. A scatterplot showing the pregnancy status of embryos according to diameter and treatment is presented in Fig. 2.

Temperatures recorded by temperature loggers packaged as for the three overnight treatments and for the shipment of embryos for transfer are presented in Fig. 3.

\section{Day-7 embryos}

After obtaining the above results with Day- 6 embryos, embryos were recovered from mares on Day 7 . All Day-7 embryos used for this study were expanded blastocysts with a tight capsule and either no zona or a thin, attenuated zona, often incomplete and in the process of flaking from the capsule (Fig. 1e). The embryos ranged from 297 to $611 \mu \mathrm{m}$ in diameter at the time of biopsy. Biopsy of these embryos necessitated puncturing of the capsule; initially this required up to three attempts at increasing settings of the Piezo drill for both speed and intensity. With experience, most biopsies could be obtained in one attempt. Drilling the hole in the capsule did not cause the capsule to tear. After the capsule was penetrated, the trophoblast cells were aspirated. When the trophoblast cells were aspirated, blastocoele fluid was lost, and the blastocyst decreased in diameter or collapsed (Fig. 1f).

Day-7 embryos in the overnight holding group were intended to be placed in the DMEM/F-12-warm overnight treatment as used for Day- 6 embryos; however, at the time the first Day-7 embryo was recovered, no DMEM/F-12 was available, so this embryo was shipped warm overnight in commercial holding medium. This embryo was an expanded blastocyst with a diameter of $442 \mu \mathrm{m}$ at the time of biopsy. After biopsy, it was shipped for transfer, and it produced pregnancy that progressed normally to the heartbeat stage. Therefore, we repeated this procedure (Holding medium-warm) for five more Day-7 embryos. The additional embryos were 297, 300, 421,464 , and $611 \mu \mathrm{m}$ in diameter at the time of biopsy. Three embryos were measured both before and after 
Table 1 Results of transfer of biopsied embryos held in different treatments before and after biopsy.

\begin{tabular}{|c|c|c|c|c|c|c|c|}
\hline $\begin{array}{l}\text { Embryo } \\
\text { age }\end{array}$ & $\begin{array}{l}\text { Overnight } \\
\text { treatment }\end{array}$ & $n$ & Diameter $(\mu \mathrm{m})$ & Embryo stage & $\begin{array}{l}\text { Shipment } 4-6 \mathrm{~h} \\
\text { before transfer }\end{array}$ & Pregnant $(n)$ & $\begin{array}{c}\text { Pregnant with } \\
\text { heartbeat }(n)\end{array}$ \\
\hline \multirow[t]{4}{*}{ Day 6} & None & 3 & $168-198$ & $1 \mathrm{LM}, 2 \mathrm{~EB}$ & Yes & 3 & 3 \\
\hline & Holding medium-cold & 3 & 159-172 & $3 \mathrm{M}$ & Yes & 0 & 0 \\
\hline & $\begin{array}{l}\text { DMEM/F-12-room } \\
\text { temperature }\end{array}$ & 3 & 169-190 & $1 \mathrm{M}^{\mathrm{a}}, 1 \mathrm{LM}, 1 \mathrm{~EB}$ & Yes & 1 & 1 \\
\hline & DMEM/F-12-warm & 3 & $188-245$ & 3 EB & Yes & 2 & 2 \\
\hline \multirow[t]{2}{*}{ Day 7} & None & 6 & $300-580$ & 6 ExpB & No & 5 & 5 \\
\hline & Holding medium-warm & 6 & $297-611$ & 6 ExpB & Yes & 5 & 5 \\
\hline \multirow[t]{2}{*}{ Day 8} & None & 2 & $790-1350$ & 2 ExpB & Yes (culture) & 2 & 2 \\
\hline & Holding medium-warm & 2 & $876-1153$ & 2 ExpB & Yes & 1 & 0 \\
\hline
\end{tabular}

M, morula (zona only); LM, late morula (zona plus capsule); EB, early blastocyst (zona plus capsule); ExpB, expanded blastocyst (tight capsule with no zona or attenuated zona).

${ }^{\mathrm{a}}$ Embryo of this group that produced pregnancy.

shipment; these embryos increased in diameter from an average size of $350 \mu \mathrm{m}$ at the time of recovery to an average size of $499 \mu \mathrm{m}$ at the time of biopsy. Overall, pregnancies were established for five of the six shipped Day-7 embryos, and all of these pregnancies progressed normally to the heartbeat stage. The largest Day-7 embryo $(611 \mu \mathrm{m})$ did not produce a pregnancy. Pregnancy results according to embryo diameter and treatment are presented in Fig. 2.

To determine whether overnight holding or the 4-6-h exposure to warm culture medium during shipment to the embryo transfer facility were the factors in the high pregnancy rates obtained with the Day-7 embryos, we biopsied six Day-7 embryos immediately after recovery and transferred them within $1 \mathrm{~h}$ to the recipient mares. Three embryos, 300, 430, and $430 \mu \mathrm{m}$ in diameter, were biopsied in the standard medium (CZB-M; Choi et al. 2003); two of these (both of $430 \mu \mathrm{m}$ diameter) yielded pregnancies after transfer, and both progressed to the

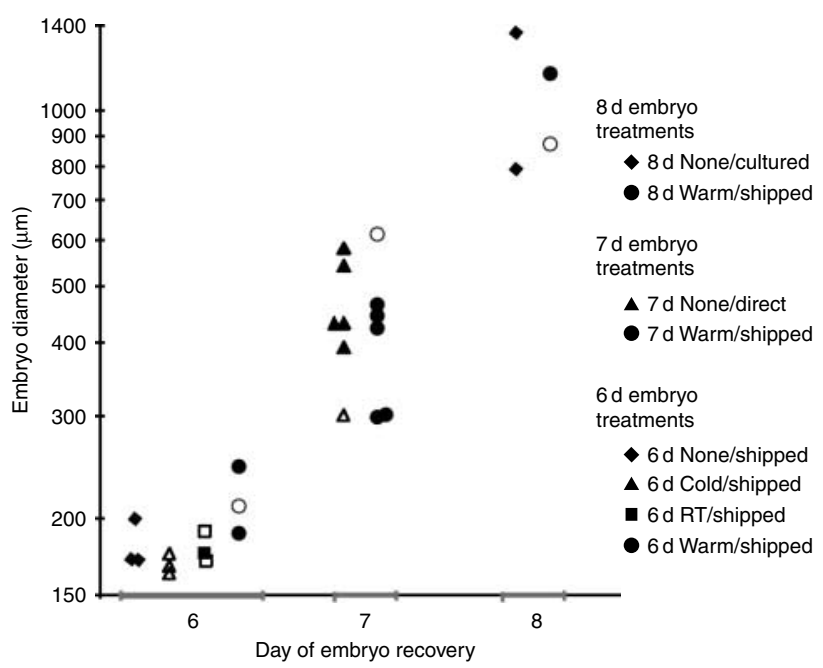

Figure 2 Scatterplot showing embryos that did (filled markers) or did not (open markers) produce pregnancies after transfer, according to embryo age, diameter, and treatment. Note logarithmic scale of $y$-axis. heartbeat stage. Three embryos, 390, 540, and $580 \mu \mathrm{m}$ in diameter, were biopsied in human tubal fluid (HTF; Fecunditas, Buenos Aires, Argentina), as used for PGD in human medicine, and all three embryos established pregnancies that progressed to the heartbeat stage.

\section{Day-8 embryos}

The four Day-8 embryos (Table 1) were large expanded blastocysts with no zona or only small shards of zona present and a tight capsule. Two were held overnight in the Holding medium-warm treatment, then were biopsied and shipped for transfer, with the larger one producing pregnancy that was lost by Day 20. The remaining two Day-8 embryos were biopsied immediately after recovery from the mare, then held in modified DMEM/F-12 at $30{ }^{\circ} \mathrm{C}$ decreasing to $25^{\circ} \mathrm{C}$ over $6 \mathrm{~h}$ to mimic the shipping environment, before transfer to the recipient mares. Both produced pregnancies that developed normally to the heartbeat stage.

\section{Birth of foals from biopsied embryos}

Nine mares that became pregnant after transfer of biopsied embryos were allowed to maintain pregnancy. These were three mares pregnant with Day- 6 embryos that had been biopsied immediately after embryo recovery, three mares pregnant with Day-6 embryos that had been held overnight before biopsy, and three mares pregnant with Day-7 embryos that had been held overnight before biopsy. All the nine pregnancies were carried uneventfully to term and resulted in the birth of healthy foals, four fillies and five colts. The gestation length was normal at $337 \pm 3 \mathrm{~d}$ (mean \pm s.D.), as were the weights of the foals at birth $(46.4 \pm 4.3 \mathrm{~kg})$. All the foals had IgG levels over $800 \mathrm{mg} / \mathrm{dl} 24 \mathrm{~h}$ after foaling. One foal contracted Salmonella enteritidis at 5 days of age and died despite treatment. The remaining foals received no medical intervention and developed normally. They were 2 years of age at the time of writing. 


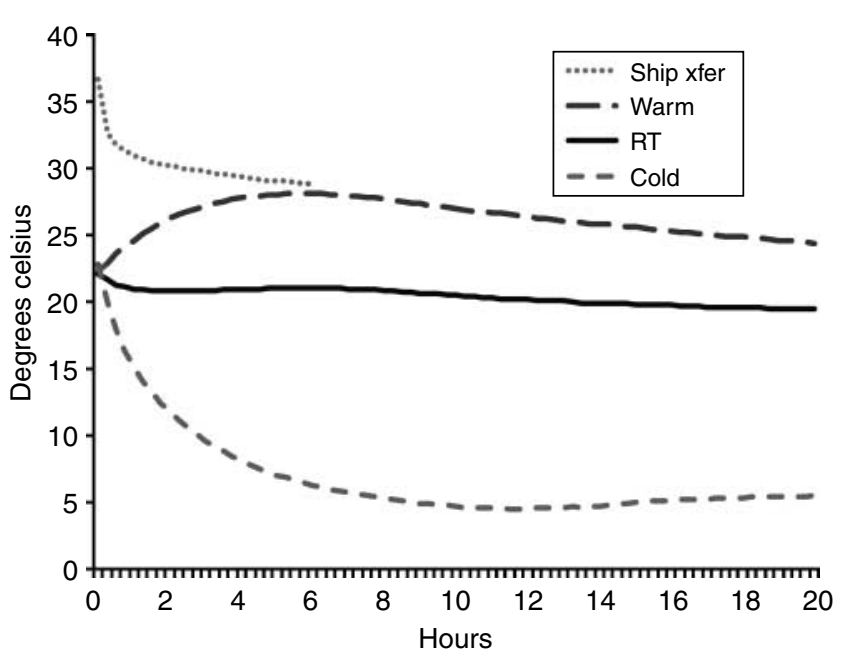

Figure 3 Temperatures recorded by temperature loggers packaged in Equitainers as for the embryo holding and shipping treatments. Ship xfer, shipping warm as performed for transfer to the recipient mares (6 h); Warm, overnight with warm coolant cans; Room temperature, overnight with room temperature coolant cans, and Cold, overnight with cold coolant cans. Equitainers were held inside at $18-25^{\circ} \mathrm{C}$ during the temperature logging period; temperatures were recorded every 15 min (hatch marks).

\section{Genetic analysis}

Twelve embryo biopsy samples were subjected to the whole-genome amplification, then were evaluated for sex and for genotype at the causative mutation site in the sodium channel, voltage-gated, type IV, alpha subunit $(S C N 4 A)$ gene, which is responsible for hyperkalemic periodic paralysis (Rudolph et al. 1992) and the peptidylprolyl isomerase B $(P P I B)$ gene, which is responsible for hereditary equine regional dermal asthenia (Tryon et al. 2007; Table 2). First, samples from four transferred embryos that did not result in foals were investigated. After whole-genome amplification, PCR for the sex-determining region $\mathrm{Y}(S R Y)$ gene determined the sex for all four embryos (three males and one female). Gene-specific PCR amplifications of the causative mutation sites were successful for the SCN4A gene in $4 / 4$ samples and for the PPIB gene in $3 / 4$ samples. The PCR products were sequenced. Results indicated that all the embryos were homozygous normal for the SCN4A gene. For the PPIB gene, results indicated that one embryo was heterozygous and the other two were homozygous normal.

Of the nine biopsy samples taken from embryos that produced foals, one was lost when the vial cracked upon thawing. Whole-genome amplification was performed on the remaining eight samples. The amplified DNA was evaluated for sex by PCR for the $S R Y$ gene. Because in this test absence of the male SRY signal could occur due to failure of the PCR, the amplified DNA was also evaluated for sex by a duplex PCR for the gene for RNA-binding motif protein, Y-linked (RBMY), which is
Y-chromosome specific, and glioma pathogenesisrelated protein 1 (GLIPR1), an autosomal gene. The sex was successfully determined in all eight samples (four males and four females), by both of the methods.

Amplification via PCR was successful for the SCN4A gene in 6/8 samples and for the PPIB gene in 7/8 samples. The PCR products of the 13 analyzable samples were sequenced. Results indicated that all six embryos were homozygous normal for the $S C N 4 A$ gene. For the $P P I B$ gene, one embryo was determined to be heterozygous, five were homozygous normal, and one was homozygous for the disease-causing allele.

DNA from blood taken from the corresponding foals was analyzed without whole-genome amplification. All the eight foals' sexes were accurately determined by duplex PCR and matched the results for the corresponding embryos. Sequencing of the SCN4A gene confirmed that foal genotype agreed with the results available from the six corresponding embryos (all homozygous normal). Sequencing of the PPIB gene revealed that five foals were homozygous normal, matching the results available from their corresponding embryos. Two foals were heterozygous for the PPIB gene. One of the corresponding embryos from these foals was determined to be heterozygous; however, the other was evaluated as homozygous for the disease-causing allele.

\section{Discussion}

In these studies, we demonstrated that breaching of the capsule of equine embryos is compatible with viability both in small, zona-enclosed embryos (Day 6) in which the capsule has not yet formed completely, and also in larger, expanded blastocysts (Day 7-8) with confluent capsules. The overall rate of normal pregnancy after transfer of biopsied Day-7 blastocysts (10 pregnancies after transfer of 12 embryos, $83 \%$ ) is noteworthy, given the importance of the capsule for the survival of this stage embryo (Stout et al. 2005). This indicates that the ability of the embryo to recover from capsular damage is likely to

Table 2 Primers used for PCR for sex determination and for amplification of the peptidylprolyl isomerase B (PPIB) and sodium channel, voltage-gated, type IV, alpha subunit (SCN4A) genes. PCR conditions were $1.5 \mathrm{mM} \mathrm{MgCl}_{2}$ and $58^{\circ} \mathrm{C}$.

\begin{tabular}{|c|c|c|}
\hline Primer set & Sequence & $\begin{array}{l}\text { Product size } \\
\text { (bp) }\end{array}$ \\
\hline$S R Y-F$ & TGCATTCATGGTGTGGTCTC & 131 \\
\hline$S R Y-R$ & ATGGCAATTTTTCGGCTTC & \\
\hline GLIPR1-F & GCCTGGATGGTTTCTTTAGTC & 113 \\
\hline GLIPR 1-R & GATCGGAACTTGTTGTGCAT & \\
\hline$R B M Y-F$ & TTCGGCCTTCTCTTTCACAT & 245 \\
\hline$R B M Y-R$ & TGGAAGCAGTCGCTATGATG & \\
\hline$P P I B-F$ & GAACATGAAGGTGCTCTTCG & 204 \\
\hline$P P I B-R$ & GTAAAGCCTCGGACACCAGT & \\
\hline SCN4A-F & GTCTTCATCATCGTCTTCACG & 344 \\
\hline$S C N 4 A-R$ & CAGGTAAATGTTTCTGGAGGTG & \\
\hline
\end{tabular}


be related to the degree of disruption. Normal pregnancies were obtained after transfer of two Day-8 biopsied blastocysts, 790 and $1350 \mu \mathrm{m}$ in diameter, suggesting that the window during which embryos can recover from compromise of capsular integrity may be quite broad. It is also notable that these pregnancies were obtained from blastocysts that had undergone partial or complete blastocoele collapse after micromanipulation. These initial findings should stimulate further work on the dynamics of equine capsule production, maintenance, and expansion. We are currently investigating the effect of capsule integrity and blastocoele collapse in relation to viability after cryopreservation of equine blastocysts.

The method used in this study, i.e. penetration of the zona or the capsule with the Piezo drill, was based on our previous work using the drill for ICSI and nuclear transfer (Choi et al. 2004, Hinrichs et al. 2006). It appeared to result in less damage to the embryo than did microblade dissection, as reported previously in the horse and other species (Huhtinen et al. 1997, Hasler et al. 2002, El-Gayar \& Holtz 2005). Biopsy via micropipette may also be preferable to chemical or laser methods to breach the zona, as are performed on human embryos (Joris et al. 2003, Spits \& Sermon 2009). The small resulting capsular defect (estimated to be $15 \mu \mathrm{m}$ in diameter, the diameter of the micropipette) either did not affect the ability of the embryo to develop in utero or was repaired. Because of the apparent folding of the capsule within zona-enclosed embryos (Fig. 1d), as previously noted after puncture of the zona by Stout et al. (2005), it is possible that multiple defects were caused by one puncture with the pipette. If the capsule is important in shielding the embryo from the maternal immune system, the induced capsular defects would have to be repaired, as maternal cells have been shown to invade through holes of similar diameter in the zona (Choi et al. 2002). The presence of shards of zona on the capsule of many Day-7 expanded blastocysts supports the theory that the zona thins and flakes off as the equine blastocyst expands in vivo. While in this study we used the Piezo drill to penetrate the capsule, this mechanism is not essential as we have subsequently successfully performed this procedure on encapsulated Day-7 equine embryos $(n=14)$ using a pointed human ICSI micropipette without a drill (YH Choi \& K Hinrichs, unpublished data).

The apparent success of overnight shipment of embryos before biopsy increases the potential for clinical application of PGD in the horse, as this supports the use of the procedure at a central laboratory, utilizing embryos shipped overnight by courier. We were initially hesitant to ship Day-6 embryos in culture medium at warm temperatures, as we felt they may develop during shipment and then be too large to biopsy the following day, thus negating the perceived benefit of obtaining the embryos at Day 6. While these embryos did grow during shipment, biopsy of Day- 6 embryos shipped in warm culture medium (modified DMEM/F-12) yielded two pregnancies from transfer of three embryos, so this did not appear to be greatly detrimental to embryo viability. While the number was low, the production of pregnancies from small embryos stored at room temperature or above (3/6) in this study is in contrast to the findings of Clark et al. (1987) who reported 0/7 pregnancies for small equine embryos stored for $12 \mathrm{~h}$ at $24^{\circ} \mathrm{C}$. The failure to produce pregnancies after cold shipment $(0 / 3)$ suggests that these conditions could be detrimental to viability of Day-6 embryos. Moussa et al. (2003) reported that small embryos showed greater cell death after cold storage than did larger embryos. Further study in this area is needed.

We initially used modified DMEM/F-12 culture medium (which supports equine embryo development in vitro; Hinrichs et al. 2005) in the warmer treatments as we felt that at warmer temperatures embryos would be metabolizing and would require a complete medium. For this reason, we were surprised by the success of the first Day-7 embryo shipped to the laboratory in the Holding medium-warm treatment. This method resulted in the $83 \%$ pregnancy rate. The finding that embryos may be shipped for biopsy in commercial holding medium makes procedures more practical, as it eliminates the concern with equilibrating a $\mathrm{CO}_{2}$-based medium.

The only established pregnancy that did not progress normally to a heartbeat stage in this study was that of a Day-8 embryo, $1153 \mu \mathrm{m}$ in diameter, that had been shipped both before and after biopsy. Further work is needed to determine if extra holding time is detrimental when larger embryos are shipped and biopsied.

All of the nine pregnancies that were allowed to be maintained were carried to term and resulted in the birth of normal foals. Amplification by duplex PCR for sex determination was successful and accurate in $8 / 8$ embryos. Duplex PCR is preferable to single SRY-PCR, as it contains a control primer set that validates that the PCR is functioning. Analysis of the embryo biopsy samples for genotype at the causative mutation sites in two genes yielded promising results, but more work is needed in this area. In 4/24 samples, PCR amplification of the gene of interest was unsuccessful. In those samples that were amplified, one embryo biopsy sample from a foal heterozygous for the PPIB gene was evaluated as having only the causative allele. The failure to detect both alleles in this biopsy sample suggests allelic dropout, which occurs when one of the alleles fails to amplify during PCR. Amplification of only one of the two alleles presents results in the samples appearing to be homozygous for the amplified allele. While the remaining 12 comparisons between the foals and the corresponding embryos at causative mutation sites matched, the presence of a high number of homozygous foals, as validated by genotyping of the foals themselves without whole-genome amplification, did not allow assessment of the frequency of allele dropout in the embryo biopsy samples. In human PGD, average allele dropout rates 
may be $5-15 \%$ or more after single-cell PCR and $25 \%$ after multiple-displacement whole-genome amplification as used in this study (reviews, Piyamongkol et al. 2003, Spits \& Sermon 2009). New techniques, including variations in methods used for cell lysis, denaturation, and processing, and multiplex PCR for detection of polymorphic markers near the loci of interest, may offer methods to reduce the incidence of allele dropout (Spits \& Sermon 2009). Further work is needed to optimize the procedures for genome amplification in horse embryo biopsy samples. Additional studies with heterozygous embryos will provide an opportunity to ascertain the rate of allele dropout with these genetic tests in horses.

In conclusion, we report here that normal viability to term may be obtained after breaching of the capsule of expanded equine embryos. We also report the results of genetic preimplantation diagnostic testing of horse embryos for traits other than sex. These findings are not only relevant to equine developmental biology, but also may prove useful to the establishment of methods for micromanipulation and cryopreservation in this species.

\section{Materials and Methods}

\section{Experimental design}

Embryos were first recovered by uterine flush on Day 6 and biopsied either immediately ( $n=3$ ) or after holding overnight $(n=9)$. Following the success of this procedure, embryos were recovered from mares on Day 7 and were either held overnight before biopsy and then shipped 4-6 $\mathrm{h}$ before transfer $(n=6)$ or biopsied immediately after recovery and transferred immediately to recipient mares $(n=6)$. Four embryos recovered from mares on Day 8 were also biopsied and transferred to recipient mares.

The first nine mares to establish pregnancy after transfer were allowed to maintain pregnancy; after this, pregnancies were monitored until the presence or absence of a heartbeat was determined, and then were terminated. Cells collected from embryos by biopsy were subjected to whole-genome amplification, and then analyzed for sex and for nucleotide sequence at two disease-causing mutation sites. The results of genetic analysis of embryo biopsy samples were compared to those obtained from blood samples taken from the resulting foals after birth.

\section{Embryo production and recovery}

Embryos were collected from inseminated mares after ovulation. Mares' reproductive tracts were evaluated by ultrasonography per rectum. On the morning that a follicle $>33 \mathrm{~mm}$ in diameter was found, ovulation was induced by injection of hCG, $2000 \mathrm{IU}$ i.v., and/or biorelease deslorelin (BETPharm, Lexington, KY, USA), $1.5 \mathrm{mg}$ i.m., and the mares were inseminated. Embryos were collected on Days 6, 7, or 8 after ovulation, by standard transcervical uterine flush. All work with mares was performed according to the United States Government Principles for the Utilization and Care of Vertebrate Animals Used in Testing, Research and Training and was approved by the Laboratory Animal Care Committee at Texas A\&M University. Some embryos were produced or transferred at commercial embryo transfer facilities (Hartman Equine Reproduction Center, Whitesboro, TX, USA, and Centro de Reproducción Equina Doña Pilar, Lincoln, Argentina). Use of the mares at these facilities was reviewed and approved by the Clinical Research Review Committee, College of Veterinary Medicine and Biomedical Sciences, Texas A\&M University.

\section{Embryo holding before biopsy}

Day-6 embryos

Three different overnight treatments were used. For each treatment, the embryo was packaged in a $5 \mathrm{ml}$ polypropylene tube in the appropriate medium (see treatments, below) at room temperature $\left(18-25^{\circ} \mathrm{C}\right)$, and this tube was placed in a $50 \mathrm{ml}$ tube containing complete equine embryo flush medium (EmCare (ICP, Auckland, New Zealand) or ViGro (Bioniche Animal Health USA, Inc., Pullman, WA, USA)), also at room temperature. The $50 \mathrm{ml}$ tube was either placed into the appropriate slot in a passive cooling device made for this purpose (Tube Style Isothermalyzer; Hamilton Research, Inc., South Hamilton, MA, USA), and a second $50 \mathrm{ml}$ tube filled with water at the same temperature placed into the second slot, or wrapped with ballast (a plastic bag containing water) at room temperature, put into a $250 \mathrm{ml}$ plastic specimen cup, and placed in a standard passive cooling device (Cup Style Isothermalizer, Hamilton Research). The devices were placed into the chamber of an insulated container (Equitainer, Hamilton Research), which had been loaded with two coolant cans at the appropriate temperature (see treatments, below). The container was closed and either held overnight or shipped overnight by courier (14-20 h) before biopsy.

The treatments used were as follows:

1. Holding medium-cold: the embryos were placed into equine embryo holding medium (EmCare Embryo Holding Solution, ICP, or Equine Holding Medium, Bioniche); coolant cans had been frozen in a $-20{ }^{\circ} \mathrm{C}$ freezer for at least $24 \mathrm{~h}$ before use.

2. DMEM/F-12-room temperature: the embryos were placed in modified DMEM/F-12 (DMEM/F-12 with $10 \%$ fetal bovine serum (FBS) and $25 \mu \mathrm{g} / \mathrm{ml}$ gentamycin). The coolant cans were at room temperature $\left(18-25^{\circ} \mathrm{C}\right)$.

3. DMEM/F-12-warm: the embryos were placed in modified DMEM/F-12. The coolant cans had been warmed in an incubator at $38.2{ }^{\circ} \mathrm{C}$ for at least $24 \mathrm{~h}$ before use.

To estimate the temperatures experienced by the embryos during shipment, separate Equitainers were packaged as for the three treatments mentioned above, and the temperature in the area of the shipment vial was recorded by temperature loggers (TEMP101, Ever Ready Thermometer Co., Inc., Dubuque, IA, USA). Equitainers were held inside at room temperature $\left(18-25^{\circ} \mathrm{C}\right)$ during the logging period. 


\section{Overnight holding of Day-7 and -8 embryos}

Day-7 and -8 embryos to be shipped or to be held overnight before biopsy were packaged in commercial holding medium as for treatment 1, mentioned above, but with coolant cans that had been warmed in an incubator at $38.2{ }^{\circ} \mathrm{C}$ for at least $24 \mathrm{~h}$ before use (Holding medium-warm treatment).

\section{Embryo biopsy}

Biopsy was performed in CZB medium with $10 \%$ FBS, with the exception of three Day-7 embryos that were biopsied in HTF.

For biopsy, embryos were held in $50 \mu$ l droplets of medium in a Petri dish on an inverted microscope. The embryos were held with a holding pipette, and a biopsy pipette of $15 \pm 3 \mu \mathrm{m}$ external diameter, attached to a Piezo drill, was used to perform the biopsy. In embryos possessing a zona pellucida, the zona was breached by drilling with the Piezo drill at settings of speed 4, intensity 6 . In embryos having a capsule, the capsule was breached by multiple pulses with the Piezo drill at higher settings. About 10-30 embryonic cells were removed by suction. The biopsied cells were ejected into the droplet containing the embryo, then aspirated from the droplet with a fine-bore glass pipette and placed with a minimum volume of medium in a $0.2 \mathrm{ml}$ PCR tube (VWR International, West Chester, PA, USA). The tubes were frozen at $-20{ }^{\circ} \mathrm{C}$ or were snap frozen in liquid nitrogen, then transferred to another laboratory and held at $-80^{\circ} \mathrm{C}$ until genetic analysis was performed.

\section{Embryo transfer}

For transfer to the recipient mares, blastocysts were either loaded into embryo transfer guns (Agtech, Inc., Manhattan, KS, USA) and transported at ambient temperature $\sim 1 \mathrm{~h}$ before transfer or placed in $1.1 \mathrm{ml}$ equilibrated modified DMEM/F-12 at $38.2{ }^{\circ} \mathrm{C}$ in a nominal $1 \mathrm{ml}$ glass vial, wrapped in $120 \mathrm{ml}$ ballast at $38.2{ }^{\circ} \mathrm{C}$, placed in an Equitainer in which the coolant cans had been warmed to $38.2^{\circ} \mathrm{C}$, and shipped $4-6 \mathrm{~h}$ before transfer to the recipient mares. Two Day-8 embryos were placed in $1.5 \mathrm{ml}$ equilibrated modified DMEM/F-12 at $38.2{ }^{\circ} \mathrm{C}$ in nominal $1 \mathrm{ml}$ cryogenic vials (Nunc, Roskilde, Denmark), then held at $30{ }^{\circ} \mathrm{C}$ decreasing over $6 \mathrm{~h}$ to $25^{\circ} \mathrm{C}$ (similar temperatures to those obtained in the Equitainer during shipping), to mimic these conditions before transfer when an Equitainer was not available.

Embryo transfer (one blastocyst per mare) was performed transcervically. Pregnancies were evaluated by transrectal ultrasonography starting $5 \mathrm{~d}$ after transfer. After pregnancy was established in nine mares, additional pregnancies were monitored and then were terminated by injecting prostaglandin $\mathrm{F}_{2 \alpha}$ (Lutalyse, Pfizer Animal Health, New York, NY, USA), 5-10 mg i.m.

\section{Whole-genome amplification}

Genomic DNA was extracted and amplified from the biopsied embryonic cells using isothermal strand displacement amplification (Illustra GenomiPhi V2 DNA Amplification Kit; GE LifeScience, Piscataway, NJ, USA) as per the manufacturer's instructions, with the modification that cells were suspended in $9 \mu \mathrm{l}$ sample buffer and vortexed for 15-30 s prior to sample denaturation. Once the procedure was complete, the quality and concentration of the amplified genomic DNA were evaluated by agarose gel electrophoresis. Negative controls were used for every whole-genome amplification procedure to ensure that the reagents were not contaminated with extraneous DNA. In cases where relatively little DNA was obtained by the initial whole-genome amplification procedure, $1.5 \mu \mathrm{l}$ amplified DNA were used as a template for a second round of whole-genome amplification using the same kit. DNA obtained by the whole-genome amplification was used for the genetic analyses described below.

\section{SRY PCR for sex determination}

PCR was performed using equine-specific primers for $S R Y$ (Table 2; Dr Terje Raudsepp, Texas A\&M University, personal communication). The $10 \mu \mathrm{l}$ PCR mixture consisted of $1 \times$ PCR buffer (Sigma-Aldrich) with $0.2 \mathrm{mM}$ dNTPs, $0.3 \mu \mathrm{M}$ forward primer, $0.3 \mu \mathrm{M}$ reverse primer, $0.25 \mathrm{U}$ JumpStart REDTaq DNA Polymerase (Sigma-Aldrich), and 50-100 ng DNA template. The thermal profile for PCR was $95{ }^{\circ} \mathrm{C}$ for $1 \mathrm{~min}$; 30 cycles of $94{ }^{\circ} \mathrm{C}$ for $30 \mathrm{~s}, 58{ }^{\circ} \mathrm{C}$ for $30 \mathrm{~s}$, and $72{ }^{\circ} \mathrm{C}$ for $30 \mathrm{~s}$; then $72{ }^{\circ} \mathrm{C}$ for $5 \mathrm{~min}$. The PCR products were evaluated by agarose gel electrophoresis for a $131 \mathrm{bp}$ product of the $S R Y$ primers (male specific). The presence of the amplified product indicated that the embryo was male, and the absence of a PCR product indicated that the embryo was female.

\section{Duplex PCR for sex determination}

Duplex PCR was performed using the equine-specific primers that amplify RBMY and GLIPR1 (Table 2). The $10 \mu \mathrm{I} \mathrm{PCR}$ mixture consisted of $1 \times$ PCR buffer (Sigma-Aldrich) with $0.2 \mathrm{mM}$ dNTPs, $0.3 \mu \mathrm{M}$ forward primer, $0.3 \mu \mathrm{M}$ reverse primer and $0.25 \cup$ JumpStart REDTaq DNA Polymerase (Sigma-Aldrich), and 50-100 ng DNA template. The thermal profile for PCR was $95^{\circ} \mathrm{C}$ for $1 \mathrm{~min} ; 30$ cycles of $94{ }^{\circ} \mathrm{C}$ for $30 \mathrm{~s}, 58{ }^{\circ} \mathrm{C}$ for $30 \mathrm{~s}$, and $72{ }^{\circ} \mathrm{C}$ for $30 \mathrm{~s}$; then $72{ }^{\circ} \mathrm{C}$ for $5 \mathrm{~min}$. The PCR products were evaluated by agarose gel electrophoresis for a $245 \mathrm{bp}$ product of the RBMY primers (male specific) and a $113 \mathrm{bp}$ product of the GLIPR1 primers (present in all the samples). The presence of the $R B M Y$ amplicon indicated that the sample was male, and its absence indicated that the sample was female. The GLIPR1 amplicon was present in every reaction as a positive control that the PCR was successful.

\section{PCR amplification of disease-causing mutation sites}

Primers for PCR were designed to amplify the causative mutation and flanking regions in the PPIB and SCN4A genes (Table 2). The $30 \mu \mathrm{l}$ PCR mixture contained $1 \times$ PCR buffer with $0.2 \mathrm{mM} d \mathrm{NTPs}, 0.3 \mu \mathrm{M}$ forward primer, $0.3 \mu \mathrm{M}$ reverse primer, $0.50 \cup$ JumpStart REDTaq DNA Polymerase, and 50-100 ng DNA template. The thermal profile for PCR was $95^{\circ} \mathrm{C}$ for $1 \mathrm{~min} ; 30$ cycles of $94^{\circ} \mathrm{C}$ for $30 \mathrm{~s}, 58^{\circ} \mathrm{C}$ for $30 \mathrm{~s}$, and $72{ }^{\circ} \mathrm{C}$ for $30 \mathrm{~s}$; then $72{ }^{\circ} \mathrm{C}$ for $5 \mathrm{~min}$. An aliquot of each PCR product was checked on gel electrophoresis to confirm amplification. 


\section{Gene sequencing}

The PCR products of the causative mutation sites were treated to remove unincorporated nucleotides using the QIAquick PCR Purification Kit (Qiagen). Amplicons were sequenced from both directions on an ABI 3730 automated capillary DNA analyzer using the standard dye terminator sequencing technique (Applied Biosystems, Foster City, CA, USA). The $10 \mu$ sequencing reaction mixture contained $2 \mu$ l Big Dye v1.1 (Applied Biosystems), $0.5 \mu \mathrm{l}$ MasterAmp PCR Enhancer (Epicentre Technologies, Madison, WI, USA), $2 \mu \mathrm{l}$ half BD (Genetix, Boston, MA, USA), and $1 \mu \mathrm{M}$ primer. The template for the sequencing reaction was the purified PCR product; $12 \mathrm{ng}$ were used for $P P I B$, and $20 \mathrm{ng}$ were used for $S C N 4 A$. The thermal profile for the sequencing reaction was $95^{\circ} \mathrm{C}$ for $2 \mathrm{~min}$; 35 cycles of $95{ }^{\circ} \mathrm{C}$ for $30 \mathrm{~s}, 50{ }^{\circ} \mathrm{C}$ for $25 \mathrm{~s}$, and $60{ }^{\circ} \mathrm{C}$ for $4 \mathrm{~min}$; then $65{ }^{\circ} \mathrm{C}$ for $15 \mathrm{~min}$. The products of the sequencing reactions were purified to remove any unincorporated nucleotides and remaining primers by passing them through a G-50 Sephadex column, then dried and resuspended in $11 \mu \mathrm{l}$ HiDi Formamide (Applied Biosystems). The products were run on an $\mathrm{ABI} 3730$ automated capillary DNA analyzer. The sequence analysis was performed using Sequencher 4.7 (Gene Codes, Ann Arbor, MI, USA).

\section{Declaration of interest}

The authors declare that there is no conflict of interest that could be perceived as prejudicing the impartiality of the research reported.

\section{Funding}

Supported by a grant from the American Quarter Horse Foundation, by the Link Equine Research Endowment, Texas A\&M University, and by Ms Kit Knotts. We thank Ms Jody Norris for excellent technical assistance and Bioniche Animal Health for generous donation of media.

\section{References}

Albihn A, Waelchli RO, Samper J, Oriol JG, Croy BA \& Betteridge KJ 2003 Production of capsular material by equine trophoblast transplanted into immunodeficient mice. Reproduction 125 855-863. (doi:10.1530/rep.0. 1250855)

Allen WR 2010 Sex, science and satisfaction: a heady brew. Animal Reproduction Science 121 262-278. (doi:10.1016/j.anireprosci.2010. 04.178)

Babinet C \& Bordenave GR 1980 Chimaeric rabbits from immunosurgically-prepared inner-cell-mass transplantation. Journal of Embryology and Experimental Morphology 60 429-440.

Barfield JP, McCue PM, Squires EL \& Seidel GE Jr 2009 Effect of dehydration prior to cryopreservation of large equine embryos. Cryobiology $\mathbf{5 9}$ 36-41. (doi:10.1016/j.cryobiol.2009.04.003)

Battut I, Colchen S, Fieni F, Tainturier D \& Bruyas JF 1998 Success rates when attempting to nonsurgically collect equine embryos at 144, 156 or 168 hours after ovulation. Equine Veterinary Journal 25 (Supplement) 60-62. (doi:10.1111/j.2042-3306.1997.tb05102.x)

Bernoco D \& Bailey E 1998 Frequency of the SCID gene among Arabian horses in the USA. Animal Genetics 29 41-42. (doi:10.1046/j.13652052.1998.00237.x)
Betteridge KJ 2007 Equine embryology: an inventory of unanswered questions. Theriogenology 68 (Supplement 1) S9-S21. (doi:10.1016/ j.theriogenology.2007.04.037)

Betteridge KJ, Eaglesome MD, Mitchell D, Flood PF \& Bériault R 1982 Development of horse embryos up to twenty two days after ovulation: observations on fresh specimens. Journal of Anatomy 135 191-209.

Brault L \& Penedo MCT 2009 Refinement of the equine cerebellar abiotrophy locus on ECA2 by haplotype analysis. Journal of Equine Veterinary Science 29 318-319. (doi:10.1016/j.jevs.2009.04.025)

Choi YH, Love CC, Love LB, Varner DD, Brinsko S \& Hinrichs K 2002 Developmental competence in vivo and in vitro of in vitro-matured equine oocytes fertilized by intracytoplasmic sperm injection with fresh or frozen-thawed sperm. Reproduction 123 455-465. (doi:10.1530/rep. $0.1230455)$

Choi YH, Chung YG, Walker SC, Westhusin ME \& Hinrichs K 2003 In vitro development of equine nuclear transfer embryos: effects of oocyte maturation media and amino acid composition during embryo culture. Zygote 11 77-86. (doi:10.1017/S0967199403001102)

Choi YH, Roasa LM, Love CC, Varner DD, Brinsko SP \& Hinrichs K 2004 Blastocyst formation rates in vivo and in vitro of in vitro-matured equine oocytes fertilized by intracytoplasmic sperm injection. Biology of Reproduction 70 1231-1238. (doi:10.1095/biolreprod.103.023903)

Clark KE, Squires EL, McKinnon AO \& Seidel GE Jr 1987 Viability of stored equine embryos. Journal of Animal Science 65 534-542.

Denker HW 2000 Structural dynamics and function of early embryonic coats. Cells, Tissues, Organs 166 180-207. (doi:10.1159/000016732)

Eldridge-Panuska WD, Caracciolo di Brienza V, Seidel GE Jr, Squires EL \& Carnevale EM 2005 Establishment of pregnancies after serial dilution or direct transfer by vitrified equine embryos. Theriogenology 63 1308-1319. (doi:10.1016/j.theriogenology.2004.06.015)

El-Gayar M \& Holtz W 2005 Transfer of sexed caprine blastocysts freshly collected or derived from cutured morulae. Small Ruminant Research 57 151-156. (doi:10.1016/j.smallrumres.2004.06.022)

Enders AC \& Liu IKM 1991 Lodgement of the equine blastocyst in the uterus from fixation through endometrial cup formation. Journal of Reproduction and Fertility Supplement 44 427-438.

Flood PF, Betteridge KJ \& Diocee MS 1982 Transmission electron microscopy of horse embryos 3-16 days after ovulation. Journal of Reproduction and Fertility 32 (Supplement) 319-327.

Freeman DA, Weber JA, Geary RT \& Woods GL 1991 Time of embryo transport through the mare oviduct. Theriogenology 36 823-830. (doi:10.1016/0093-691X(91)90348-H)

Gardner RL \& Edwards RG 1968 Control of the sex ratio at full term in the rabbit by transferring sexed blastocysts. Nature 218 346-349. (doi:10. 1038/218346a0)

Gardner RL \& Munro AJ 1974 Successful construction of chimaeric rabbit. Nature 250 146-147. (doi:10.1038/250146a0)

Goossens V, Harton G, Moutou C, Traeger-Synodinos J, Van Rij M \& Harper JC 2009 ESHRE PGD Consortium data collection IX: cycles from January to December 2006 with pregnancy follow-up to October 2007. Human Reproduction 24 1786-1810. (doi:10.1093/humrep/dep059)

Hasler JF, Cardey E, Stokes JE \& Bredbacka P 2002 Nonelectrophoretic PCR-sexing of bovine embryos in a commercial environment. Theriogenology 58 1457-1469. (doi:10.1016/S0093-691X(02)01044-0)

Herrler A \& Beier HM 2000 Early embryonic coats: morphology, function, practical applications. An overview. Cells, Tissues, Organs 166 233-246. (doi:10.1159/000016736)

Herszberg B, McCue ME, Larcher T, Mata X, Vaiman A, Chaffaux S, Chérel Y, Valberg SJ, Mickelson JR \& Guérin G 2009 A GYS1 gene mutation is highly associated with polysaccharide storage myopathy in Cob Normand draught horses. Animal Genetics 40 94-96. (doi:10.1111/ j.1365-2052.2008.01778.x)

Hinrichs K, Choi YH, Love LB, Varner DD, Love CC \& Walckenaer BE 2005 Chromatin configuration within the germinal vesicle of horse oocytes: changes post mortem and relationship to meiotic and developmental competence. Biology of Reproduction 72 1142-1150. (doi:10.1095/ biolreprod.104.036012)

Hinrichs K, Choi YH, Love CC, Chung YG \& Varner DD 2006 Production of horse foals via direct injection of roscovitine-treated donor cells and activation by injection of sperm extract. Reproduction 131 1063-1072. (doi:10.1530/rep.1.01095) 
Huhtinen M, Peippo J \& Bredbacka P 1997 Successful transfer of biopsied equine embryos. Theriogenology 48 361-367. (doi:10.1016/S0093691X(97)00247-1)

Iuliano MF, Squires EL \& Cook VM 1985 Effect of age of equine embryos and method of transfer on pregnancy rate. Journal of Animal Science $\mathbf{6 0}$ 258-263.

Joris H, De Vos A, Janssens R, Devroey P, Liebaers I \& Van Steirteghem A 2003 Comparison of the results of human embryo biopsy and outcome of PGD after zona drilling using acid Tyrode medium or a laser. Human Reproduction 18 1896-1902. (doi:10.1093/humrep/deg355)

Maclellan LJ, Carnevale EM, Coutinho da Silva MA, McCue PM, Seidel GE Jr \& Squires EL 2002 Cryopreservation of small and large equine embryos pre-treated with cytochalasin-B and/or trypsin. Theriogenology $\mathbf{5 8}$ 717-720. (doi:10.1016/S0093-691X(02)00920-2)

McKinnon AO \& Squires EL 1988 Equine embryo transfer. Veterinary Clinics of North America 4 305-333.

McKinnon AO, Carnevale EM, Squires EL, Carney NJ \& Seidel GE Jr 1989 Bisection of equine embryos. Equine Veterinary Journal 8 (Supplement) 129-133. (doi:10.1111/j.2042-3306.1989.tb04697.x)

Moens A, Betteridge KJ, Brunet A \& Renard JP 1996 Low levels of chimerism in rabbit fetuses produced from preimplantation embryos microinjected with fetal gonadal cells. Molecular Reproduction and Development 43 38-46. (doi:10.1002/(SICI)1098-2795(199601)43:1< 38::AID-MRD5 > 3.0.CO;2-V)

Moussa M, Duchamp G, Mahla R, Bruyas JF \& Daels PF 2003 In vitro and in vivo comparison of Ham's F-10, Emcare holding solution and ViGro holding plus for the cooled storage of equine embryos. Theriogenology 59 1615-1625. (doi:10.1016/S0093-691X(02)01210-4)

Müller Z \& Cikryt P 1989 A simple method for bisecting horse embryos. Equine Veterinary Journal 8 (Supplement) 123-125. (doi:10.1111/j. 2042-3306.1989.tb04695.x)

Ogilvie CM, Braude PR \& Scriven PN 2005 Preimplantation genetic diagnosis - an overview. Journal of Histochemistry and Cytochemistry $\mathbf{5 3}$ 255-260. (doi:10.1369/jhc.4B6395.2005)

Oriol JG, Betteridge KJ, Clarke AJ \& Sharom FJ 1993a Mucin-like glycoproteins in the equine embryonic capsule. Molecular Reproduction and Development 34 255-265. (doi:10.1002/mrd.1080340305)

Oriol JG, Sharom FJ \& Betteridge KJ $1993 b$ Developmentally regulated changes in the glycoproteins of the equine embryonic capsule. Journal of Reproduction and Fertility 99 653-664. (doi:10.1530/jrf.0. 0990653)

Piyamongkol W, Bermudez MG, Harper JC \& Wells D 2003 Detailed investigation of factors influencing amplification efficiency and allele drop-out in single cell PCR: implications for preimplantation genetic diagnosis. Molecular Human Reproduction 9 411-420. (doi:10.1093/ molehr/gag051)

Rudolph JA, Spier SJ, Byrns G, Rojas CV, Bernoco D \& Hoffman EP 1992 Periodic paralysis in quarter horses: a sodium channel mutation disseminated by selective breeding. Nature Genetics 2 144-147. (doi:10.1038/ng1092-144)

Skidmore J, Boyle MS, Cran D \& Allen WR 1989 Micromanipulation of equine embryos to produce monozygotic twins. Equine Veterinary Journal 8 (Supplement) 126-128. (doi:10.1111/j.2042-3306.1989.tb04696.x)

Slade NP, Takeda T, Squires EL, Elsden RP \& Seidel GE Jr 1985 A new procedure for cryopreservation of equine embryos. Theriogenology 24 45-58. (doi:10.1016/0093-691X(85)90211-0)

Spits C \& Sermon K 2009 PGD for monogenic disorders: aspects of molecular biology. Prenatal Diagnosis 29 50-56. (doi:10.1002/pd.2161)

Stout TA, Meadows S \& Allen WR 2005 Stage-specific formation of the equine blastocyst capsule is instrumental to hatching and to embryonic survival in vivo. Animal Reproduction Science 87 269-281. (doi:10. 1016/j.anireprosci.2004.11.009)

Tremoleda JL, Stout TA, Lagutina I, Lazzari G, Bevers MM, Colenbrander B \& Galli C 2003 Effects of in vitro production on horse embryo morphology, cytoskeletal characteristics, and blastocyst capsule formation. Biology of Reproduction 69 1895-1906. (doi:10.1095/biolreprod.103.018515)

Tryon RC, White SD \& Bannasch DL 2007 Homozygosity mapping approach identifies a missense mutation in equine cyclophilin B (PPIB) associated with HERDA in the American Quarter Horse. Genomics 90 93-102. (doi:10.1016/j.ygeno.2007.03.009)

Tryon RC, Penedo MCT, McCue ME, Valberg SJ, Mickelson JR, Famula TR, Wagner ML, Jackson M, Hamilton MJ, Nooteboom S et al. 2009 Evaluation of allele frequencies of inherited disease genes in subgroups of American Quarter Horses. Journal of the American Veterinary Medical Association 234 120-125. (doi:10.2460/javma.234.1.120)

Ward TL, Valberg SJ, Adelson DL, Abbey CA, Binns MM \& Mickelson JR 2004 Glycogen branching enzyme (GBE1) mutation causing equine glycogen storage disease IV. Mammalian Genome 15 570-577. (doi:10. 1007/s00335-004-2369-1)

Received 15 March 2010

First decision 23 April 2010

Revised manuscript received 3 September 2010

Accepted 15 September 2010 